Иванова Елена Юрьевна

Ivanova Yelena Yuryevna

кандидат экономических наук,

старший научный сотрудник института социологии

Федерального научно-исследовательского

социологического центра

Российской академии наук (ФНИСЦ РАН)

\section{СЕМЕЙСТВЕННОСТЬ (НЕПОТИЗМ) КАК ДЕСТРУКТИВНАЯ ФОРМА ПРОФЕССИОНАЛЬНЫХ ДИНАСТИЙ: ГОСУДАРСТВЕННАЯ ПОЛИТИКА И ОБЩЕСТВЕННОЕ MHЕНИЕ}

\section{Аннотация:}

В статье изучаются феномен семейственности как деструктивной формы профессиональной преемственности, а также методы государственной политики по ограничению возможности формирования и поддержки профессиональных династий в целях противодействия коррупционным проявлениям. Подводя итоги анализа современного законодательства, направленного против непотизма как формы конфликта интересов личности и общества, его влияния на процессы семейной профессиональной преемственности, автор отмечает как отсутствие в настоящее время единой правоприменительной практики, так и недостаточную оценку отраслевых особенностей проявления коррупиии, негативное воздействие на факторы возникновения и поддержки профессиональных династий в сфере интеллектуального труда. Глобальные интересы социума и локальные интересы семьи требуют серьезных многофакторных исследований (в сегментах права, психологии, конфликтологии, социологии, экономики, политологии) возможных путей разрешения конфликта между феноменами семейственности и династийности в различных профессиональных областях.

\section{Ключевые слова:}

профессиональная династия, непотизм, семейственность, клановость, социальный статус, коррупция, социальная мобильность.
PhD in Economics, Senior Research Fellow, Institute of Sociology, Moscow Federal Research Sociological Center of the Russian Academy of Sciences

NEPOTISM AS A DESTRUCTIVE FORM OF PROFESSIONAL DYNASTIES: STATE POLICY AND SOCIAL OPINION

\begin{abstract}
Summary:
The paper analyzes the phenomenon of "nepotism" as a destructive form of professional succession, as well as the methods of state policy to limit the possibility of forming and supporting professional dynasties in order to counteract corruption. In summing up the analysis of modern legislation against nepotism as a form of conflict of interests of individuals and society, its impact on the processes of family professional succession, the author notes the current lack of a unified law enforcement practice, as well as an insufficient assessment of the sectoral features of corruption, the negative impact on the factors of the emergence and support of professional dynasties in the field of intellectual labor. Global interests of society and local interests of the family require serious multi-factor research (law, psychology, conflictology, sociology, economics, political science) of possible ways to resolve the conflict between the phenomena of nepotism and dynasties in various professional fields.
\end{abstract}

Keywords:

professional dynasty, nepotism, cronyism, social status, corruption, social mobility.

Анализ проблем и особенностей формирования профессиональных династий, рассматриваемых как социальный феномен, а также конкретизация условий их функционирования в историческом контексте с учетом практик социально-экономического регулирования позволили систематизировать показатели эффеективности семейной профессиональной преемственности и рассмотреть методы и способы их государственной поддержки, нацеленной на достижение социально-политических и экономических целей развития [1].

Профессиональные династии как социальный механизм воспроизводства профессиональных групп базируются на следующих факторах внутрисемейного взаимодействия.

1. Передача алгоритма профессионального самоопределения в рамках жесткого следования профессиональной стратегии, выработанной поколениями, наследование образовательной траектории и сферы профессиональной реализации.

2. Наследование профессиональных компетенций, этических норм и ценностей профессии родителей. 
3. Оценка молодым поколением значимости профессиональной преемственности и сопричастности к историческим достижениям семейной династии способствует более успешной самореализации и мотивации на продолжение профессиональных традиций. Принадлежность к профессиональной династии рассматривается как важный фактор восходящей социальной мобильности.

4. Анализ психологических особенностей взаимодействия подростков и родителей в процессе профессионального самоопределения в семьях, ориентированных на профессиональную преемственность, показывает, что формируется особый тип человека с преобладанием духовных мотивов выбора профессиональной траектории над материальными; необходимостью чувствовать себя компетентной, социальной и ответственной личностью; доминантой контроля за свою жизнь, ответственности за принятие решений и воплощение их на практике; стремлением к гармоничному бытию и здоровым отношениям с людьми; «гипертрофированным желанием ребенка оправдать возложенные на него надежды, ожидания родителей» [2]. При этом родители ориентированы на лидерство в отношениях путем завоевания авторитета, основанного на фактических достижениях и доминантном стиле общения, на позитивном интересе, лишенном грубой силы и нераздельной власти над ребенком.

5. Профессиональная династия воспроизводит способствующую ее эффективному существованию социальную инфраструктуру: профессиональный круг общения с последователями и единомышленниками; налаженные связи в узкопрофессиональной среде, а также контакты, способные обеспечить протекцию, покровительство, удачный профессиональный старт, продвижение по служебной лестнице и получение выгодных предложений на рынке труда.

Однако положительная коннотация описываемых процессов сосуществует с негативными примерами использования преимуществ профессиональной династии в корыстных целях. Наравне с государственной и ведомственной политикой поддержки профессиональной преемственности имеются механизмы, ограничивающие расширение сферы ее влияния в интересах общественного развития. В отечественной научной литературе отсутствуют системные исследования, посвященные критическому анализу реальных социально-экономических мер, препятствующих воспроизводству социальной инфраструктуры профессиональной династии. Например, ограничения распространяются на область государственных услуг, армию, суды. При этом недостаточное внимание уделяется изучению деструктивных видов профессиональных династий. Одной из таких форм, базирующихся на использовании родственных профессиональных связей для обеспечения восходящей социальной мобильности и обогащения членов семьи, является семейственность, или непотизм, - служебное покровительство родственников, замещение должностей предпочтительно родственниками в нарушение общего и справедливого порядка, без учета знаний, способностей соискателя.

Важность фрактора семьи в самоопределении молодого поколения можно проиллюстрировать результатами массового опроса рядовых инженеров, студентов инженерных специальностей и преподавателей вузов, проведенного ФНИСЦ РАН в 2016-2017 гг. в рамках исследования «Инженерные династии России» (грант РГНФ № 15-03-00666) [3]. Одним из преимуществ профессиональной династии респонденты считают помощь родителей и родственников, обеспечивающую восхождение по карьерной лестнице. В качестве главного фактора поступления в вуз содействие родителей, родственников и знакомых отметили 23 \% опрошенных, 31 \% устроились на работу благодаря родственникам и знакомым.

Непотизм (семейственность, фаворитизм, кумовство, блат) по большей части рассматривается как одна из форм проявления девиантного поведения, коррупции. Конфликт интересов семьи и государства приводит к необходимости правового регулирования трудовых отношений, обеспечивающих противодействие непотизму.

Экономическая система производства и распределения накладывает отпечаток на особенности проявления и масштабы анализируемого социального поведения. Так, в условиях капиталистических реалий этим термином «обозначают рыночную экономику, в условиях которой успех в бизнесе (в том числе получение лицензий, государственных заказов, субсидий, кредитов и т. п.) зависит только и исключительно от личных связей бизнесменов с государственными служащими» [4]. По данным Федерального управления кадровой службы Правительства США за 2002 г. только 36,1 \% гражданских чиновников продвигались по служебной лестнице благодаря своим профессиональным заслугам [5], остальные - исходя из личных симпатий и родственных связей вышестоящих руководителей. Однако не только капитализм «грешит» явлениями непотизма. Данная категория, сформировавшаяся в Средние века, идентифицирует отношения фраворитизма, которые возникали и возникают между людьми при любой фрорме общественного воспроизводства, в том числе социализме.

Мы проанализировали законодательство СССР и Российской Федерации по ограничению практики совместной службы родственников в государственных учреждениях, которая может 
привести или приводит к некомпетентным решениям, незаконному обогащению, отсутствию адекватных оценок деловых и профессиональных качеств. Следование этому правовому механизму, с одной стороны, создавало условия для ограничения возможности коррупционных проявлений, а с другой - возводило препятствия для возникновения и поддержки профессиональной династийности в ряде сфер человеческой деятельности.

27 июля 2018 г. был принят декрет за подписью председателя Совета народных комиссаров Вл. Ульянова (Ленина) о недопустимости совместной службы родственников в советских учреждениях [6]. Согласно этому документу, не могли состоять на службе в одной и той же как центральной, так и местной организации «лица, находящиеся в родстве или свойстве с кем-либо из ответственных руководителей данного учреждения». Во исполнение этого декрета в течение двух недель сотрудники, не удовлетворяющие декларируемым требованиям, должны быть уволены, а «лица, виновные в нарушении настоящего декрета, подлежат немедленному устранению от должностей. В особо важных случаях виновные предаются суду революционного трибунала».

Причины подобной жесткой политики кроются в убежденности, что родственные связи снижают исполнительскую дисциплину, создают условия для злоупотреблений различного рода. При формировании новых советских управленческих институтов предпринимались усилия для ограничения возможных негативных корпоративных действий, связанных в том числе с классовым подходом в кадровой политике. Нельзя было допустить обуржуазивания и аристократизации управленческого аппарата, враждебных новому советскому порядку. Таким образом сформировалась институция разрушения преемственности на государственной службе и в учреждениях непроизводственной сферы, находящихся на бюджетном финансировании. Одновременно в обществе возникла модель стереотипного негативного (беззаконие, вредительство, коррупция, блат, несправедливость, классовая нетерпимость) отношения населения к возможному сохранению династий в указанных областях профессиональной реализации.

Рьяное и неукоснительное следование букве этого документа привело на местах к существенным перекосам. В связи с этим требовались некоторые уточнения и корректировка правоприменительной практики, оформлялись изъятия из действующего порядка образования кадрового корпуса советских учреждений, смягчались ограничения совместной службы родственников в случаях острого недостатка рабочих рук с разрешения руководства, за подписью всех членов коллегии и «с непременным сообщением копии постановления в каждом отдельном случае в Народный Комиссариат Рабоче-Крестьянской Инспекции, Всероссийский Центральный Совет Профессиональных Союзов и Народный Комиссариат Труда» [7]. Таким образом, вводилась коллективная ответственность за возможное ослабление практик регулирования кадровой семейной политики на местах и случаи коррупционных действий.

Дальнейшая регламентация и уточнение правоприменительной практики последовали после принятия декрета от 21 декабря 1922 г. «Временные правила о службе в государственных Учреждениях и предприятиях» [8], Кодекса законов о труде 1972 г. [9]. Смягчение трудового законодательства выражалось в распространении запрета только на случаи непосредственной служебной подчиненности или подконтрольности родственников.

Ограничительные меры косвенно, опосредованно были направлены на разрушение механизмов формирования профессиональных династий в сфере государственной службы. Кардинальным образом изменилась исторически сложившаяся система преемственности государственного служения в дореволюционной России как обязательной повинности и наследования социального статуса, образовательной траектории, титула и пр. Были созданы юридические и социальные препятствия процессам восходящей социальной мобильности для представителей ряда профессий и бывших сословий и чинов, прервались династийные связи (декрет советской власти «Об уничтожении сословий и гражданских чинов» от 11 ноября 1917 г. [10]). Для малых городов с естественным дефицитом рабочих мест такая политика не только приводила к невозможности реализовать себя представителям молодого поколения в соответствии с семейными традициями и предпочтениями, прежде всего в области интеллектуального труда, но и способствовала снижению общего образовательного уровня государственного служащего.

Запрет на совместную работу (как правило, работникам интеллектуального, творческого труда), если она предполагала непосредственную подчиненность или подконтрольность одного из родственников другому, привел к тому, что, например, в малокомплектной сельской школе, поселковом медицинском учреждении, клубе закону следовать было невозможно из-за отсутствия кадрового маневра (некому учить, некому лечить). Это обусловливало либо противозаконные действия, либо разрушение системы образования и здравоохранения.

В целях корректировки и смягчения складывающейся ситуации 21 августа 1972 г. было принято постановление Совета министров РСФСР «Об изъятиях из правила об ограничении совместной службы родственников» [11]. Исключения были сделаны, например, для работников 
сельского, лесного, водного и паркового хозяйства, для эксплуатационщиков в сферах дорожного строительства, транспорта, связи, за исключением бухгалтеров, кассиров и руководителей.

Особое внимание стоит уделить следующим изъятиям из правил. Важен не только факт включения ряда уважаемых профессий в этот список, но и то, что начиная с 1922 г. (т. е. в течение 50 лет) эти профессии в список изъятий не входили: врачи лечебно- и санитарно-профилактических учреждений здравоохранения; педагогические работники, преподаватели, библиографы и библиотекари во всех учебных и воспитательных организациях; артисты, художники и музыканты государственных театров, художественных коллективов и студий. «Исключения касались большого количества работников, что обусловливалось различными факторами: ограниченностью трудовых ресурсов в соответствующих местностях, особым режимом работы, спецификой выполняемой трудовой функции, преемственностью поколений в отдельных сферах общественной жизни и другими обстоятельствами» [12]. Однако ограничения не распространились, например, на сотрудников научных учреждений Академии наук СССР (за исключением находящихся в районах Крайнего Севера и на других экстремальных климатических территориях), систему муниципальной и государственной гражданской службы, полицию, следственный комитет, прокуратуру, а также на судейский корпус. Объяснение необходимости не распространять на представителей этих видов деятельности упомянутых изъятий, на наш взгляд, свидетельствует не столько о борьбе с коррупционными схемами, семейственностью, сколько о целенаправленном затормаживании процессов формирования стойких элитарных групп вне сферы материального производства.

Главной задачей принятого в 2002 г. Трудового кодекса Российской Федерации стало урегулирование трудовых отношений в основном в негосударственном секторе экономики. В документе была закреплена недопустимость любой дискриминации в трудовой деятельности: «Никто не может быть ограничен в трудовых правах и свободах или получать какие-либо преимущества независимо от пола, расы, цвета кожи, национальности, языка, происхождения, имущественного, социального и должностного положения, возраста, места жительства, отношения к религии, политических убеждений, принадлежности или непринадлежности к общественным объединениям, а также от других обстоятельств, не связанных с деловыми качествами работника» [13]. Однако в этом достаточно широком социально-демографическом списке не присутствует родственно-семейная тема. Из опыта юридической трактовки положений и буквы закона следует, что отсутствие в перечне, списке, реестре, его статьях некоего возможного варианта события, формы или вида субъекта или объекта процесса, особенностей реализации регулируемой деятельности означает лишь одно - на неуказанные (забытые, намеренно или ненамеренно пропущенные положения) действие этого закона не распространяется. Разрешено все, что не запрещено. Отсутствие семейно-родственного контекста в законе может выводить и выводит в ряде случаев возникающие отношения работодателя и претендента на конкретное рабочее место за пределы действия либерального трудового законодательства. Очевидно, что не существует прямо пропорциональной зависимости между наличием коррупционной составляющей в работе предприятия, учреждения или организации и наличием или отсутствием признаков родства или свойства в трудовом коллективе.

Одновременно с этим необходимо отметить, что феномен профессиональной династии стимулирует повышение компетенции ее членов и увеличивает эффективность конечного результата хозяйствующего субъекта. Хотя ограничение совместной службы родственников и свойственников не имеет ничего общего с оценкой их деловых качеств, вместе с тем нельзя отрицать, что их взаимоотношения в процессе исполнения трудовых обязанностей могут носить особый характер, трансформирующийся в фрормулу «рука руку моет». Законодательный маневр, регулирующий эти противоречия, зафиксирован в статье 3 Кодекса, посвященной ограничительному толкованию понятия трудовой дискриминации [14], федеральных законах «О государственной гражданской службе Российской Федерации» [15] и усилен законом «О противодействии коррупции» [16]: «Гражданин не может быть принят на гражданскую службу, а гражданский служащий не может находиться на гражданской службе при близком родстве или свойстве (родители, супруги, дети, братья, сестры, а также братья, сестры, родители, дети супругов и супруги детей) с гражданским служащим, если замещение должности гражданской службы связано с непосредственной подчиненностью или подконтрольностью одного из них другому», что может спровоцировать конфликт интересов, связанный с ненадлежащим исполнением возложенных на него обязательств из-за доминирования личной заинтересованности (виртуальная возможность получения преимуществ и выгод (денежных и неденежных) над беспристрастным исполнением должностных обязанностей. Контроль за семейно-родственными отношениями распространился не только на учреждение или организацию, но и на иные хозяйствующие субъекты, связанные по вертикали и горизонтали с этой хозяйствующей единицей. В условиях глобализации экономического развития эти требования как невыполнимы, так и неподконтрольны. 
Постановление Правительства РФ № 568, регламентирующее распространение на отдельные категории граждан ограничений, запретов и обязанностей [17], было воспринято как разрушающее традиции профессиональной преемственности и династийности в сфере культуры и искусства, кинематографии, музейного и библиотечного дела. Министерством труда и социального развития разработан альтернативный проект (не принятый) «в целях сохранения традиций и исторической преемственности поколений в сферах науки, образования, здравоохранения, культуры и социальной защиты. Деятельность в сфрерах науки, образования, здравоохранения, культуры и социальной защиты имеет особенности, связанные с исторически сформировавшимися творческими или профессиональными династиями. При этом действующий запрет на осуществление совместной трудовой деятельности с близкими родственниками не способствует сохранению и преемственности поколений» [18, с. 111]. В конечном счете в пресловутое постановление № 568 были внесены утоняющие положения о распространении его действия только на руководителей, главных бухгалтеров и должности, связанные с осуществлением фринансово-хозяйственных полномочий.

Ограничения, послабления, изъятия в законодательстве, противодействующем коррупции и семейственности, не распространяются на многие виды деятельности. Например, кандидатом на должность судьи не может быть лицо, состоящее в близком родстве или свойстве с председателем или заместителем председателя того же суда. Специальная квалификационная коллегия судей в свое время приняла решение о расширении запрета на работу в одном учреждении на адвокатуру и крупные юридические службы, ввела так называемый «родственный фильтр». Таким образом был закрыт социальный лифт для многих судей и разрушилась династийная преемственность в сфере юриспруденции, а кандидаты на должности судей шутили, «что идеальный служитель Фемиды должен быть круглым сиротой» [19]. Мнение участников круглого стола, организованного Советом Федерации РФ, выразил зампред комитета по конституционному законодательству и госстроительству В.В. Полетаев, подчеркнув, что нынешнее законодательство, «выискивая конфликт интересов», часто «уничтожает семейные трудовые династии, загоняя судей, прокуроров и юристов в угол... Родители не могут гордиться своей профессией, много разрушенных семей, фриктивных разводов, дети вынуждены переезжать в другие регионы. Получается, что идеальный судья, прокурор, госслужащий - круглый сирота» [20].

Подводя итоги анализа законодательства, направленного против непотизма как формы конфликта интересов личности и общества, его влияния на процессы семейной профессиональной преемственности, следует отметить отсутствие в настоящее время единой правоприменительной практики, недостаточную оценку отраслевых особенностей и масштабов проявления коррупции, негативное воздействие на факторы формирования и поддержки профессиональных династий в сфере интеллектуального труда. Таким образом, с одной стороны, любые отношения, возникающие в системе госслужбы, а также на предприятиях и в учреждениях, существующих за счет бюджетного финансирования, связанные с родственными связями и контактами, заведомо трактуются как клановые и коррупционные, пресекаются на корню, что, на наш взгляд, ошибочно. С другой стороны, информационный фон, поддерживаемый средствами массовой информации, активно формирует стереотипное общественное мнение о негативной роли семейных, родственных связей в области оперативного и перспективного управления государственными организациями и предприятиями, социально-экономическим развитием страны в целом.

Крупнейшие социологические центры в связи с намерением запретить в Государственной думе и Совете Федерации работать в качестве депутатов и сенаторов родственникам, провели опросы, анализ результатов которых приведен далее. По данным «Левада-центра», если в 2000 г. $18 \%$ респондентов указывали на "семейственность, кумовство» как причину коррупции, то в 2014 г. - уже 31 \% [21]. Фонд «Общественное мнение» (далее - ФОМ) провел опрос «Семейственность на работе и в Госдуме» [22]. 32 \% участников исследования, т. е. третья часть населения, когда-либо работали или работают в одной организации или на предприятии вместе с членами семьи, что свидетельствует о масштабах распространенности семейственности в России. Были отмечены следующие положительные фракторы совместной работы родственников: взаимопомощь, поддержка, слаженность действий, общие интересы, взаимопонимание, доверие $(27 \%)$ (среди вариантов ответов, подтверждающих роль совместной работы в обеспечении профессиональной преемственности, был, например, такой: «советуются друг с другом, можно передать опыт»); укрепление семейных отношений (4); больше ответственности и заинтересованности в работе, преемственность, трудовая дисциплина (4 \%) (среди вариантов ответов: «если судить по прошлому, когда были династии - это хорошо»). Опрошенные отметили следующие отрицательные стороны работы членов семьи в одной организации: берут на работу только своих, невозможность устроиться другим людям, делают поблажки родственникам, знакомым, прикрывают даже в ущерб работе (9 \%); коррупция, махинации (4); постоянный контроль, зависимость, несвобода, ухудшение 
семейных отношений (24 \%). В общей сложности треть респондентов ответили, что работать с родственниками хорошо, треть - плохо, еще треть - не определились.

В случае когда респонденты высказывают мнение о проблеме семейственности на «нижнем», бытовом уровне профессиональной самореализации, наблюдается взвешенная и аргументированная реакция. Когда выясняется отношение опрашиваемых к возможному запрещению членам одной семьи (супругам, близким родственникам) быть депутатами Госдумы РФ, тон ответов, аргументация кардинально дрейфуют к безапелляционному негативу. 51 \% участников исследования полностью поддерживает эту инициативу: «не будет семейных кланов»; «ни к чему родственность разводить»; «люди, связанные с руководством страной, политикой, начнут прикрывать друг друга, делать поблажки»; «закроется одна из лазеек для коррупции»; «а то сидят все семьями, деньги гребут, а не работают»; «им и так денег хватит, а то вдвоем еще больше наворуют»; «много привилегий для одной семьи»; «потому что и так много льгот и всего прочего»; «две неприкосновенности - это круто». 11 \% опрошенных не поддерживают инициативу и считают, «что если люди могут принести пользу обществу, то они могут работать вместе»; «если оба достойные, то пусть работают»; «если есть мозги и опыт, пусть работают»; «а может быть, умный человек в семье - и ему уже нельзя?»; «затрагивает право другого человека на право выбора»; «каждый добивается и имеет свои права - это будет ущемление прав»; «они имеют право работать. Другое дело, что это не стоит поощрять».

ВЦИОМ подтвердил выводы фонда «Общественное мнение», опросив россиян с целью выяснить их отношение и аргументацию за запрет близким родственникам работать вместе на высших государственных постах и против него. 75 \% респондентов поддерживают данную инициативу, поскольку это поможет в борьбе с коррупцией и клановостью; блатом (49); в большую политику станет проще попасть новым людям (11); на работе станут больше думать о благе государства, а не о проблемах семьи, ее обогащении (5 \%). 12 \% участников исследования, не поддерживающих эту инициативу, считают, что родственные связи не мешают работе; той же точки зрения придерживаются опрошенные, «если работник хороший» (10), «все равно они друг другу будут помогать, в политике чужих людей нет» (2), затруднились ответить - 88 \% [23].

Таким образом, респонденты оценивают, с одной стороны, семейственность с точки зрения реальной возможности получения необоснованной и несправедливой материальной выгоды, льгот и преференций, с другой - эффрективность, пользу для дела, государственный подход в выработке стратегии развития и право назначения на должности компетентных работников. Проанализированное антикоррупционное законодательство было направлено на снижение риска противозаконной составляющей в кадровой политике, при этом оказалось, что только 4 \% респондентов (по сведениям ФОМ) характеризуют семейственность как коррупционный фактор. На наш взгляд, это косвенно подтверждает гипотезу о неэффективности и недальновидности государственной политики по формированию общественного мнения о негативном отношении к семейным производственным связям. Принципиальные различия между данными ФОМ и «Левада-центра» связаны с тем, что первый использует открытые вопросы, а второй - закрытые. Тем самым участник исследования в первом случае находился в более комфортной независимой ситуации опроса, а во втором - был ограничен заранее подготовленными вариантами возможных ответов.

Кроме офрициальных данных социологических опросов, мы проанализировали дискуссии на интернет-фрорумах (30 источников), посвященных обсуждению проблем законодательства, ограничивающего работу родственников на одном предприятии, а также семейственности в разных профессиональных средах и роли профессиональных династий. Структуризация мнений позволила сформировать некий реестр, спектр агрегированных оценок пользователей Всемирной сети указанных проблем [24]. Далее приведены примеры общественного обсуждения.

1. Отсылка к периоду существования СССР: «при СССР клановость тоже была, но в куда меньших масштабах. А семейственности и вовсе не было»; «в СССР был хороший закон, мудрый закон, запрещающий брать на работу родственников»; «из-за нарушения закона снимали с должности, хотя были пути обхода закона, если родственники имели разные фрамилии, но до первого "прокола"»; «для рабочих специальностей закон не действовал, даже приветствовался. "Династия" было почетное звание».

2. Негативные черты семейственности: «работа родственников на госпредприятии порождает сплетни, нездоровые отношения, зависть, несправедливость в коллективе, очевидное неравноправие, доносительство, обиду»; «сейчас отношение к работе другое, это раньше все держалось на энтузиазме, а сейчас - рука руку моет, а свой своего кроет»; «семья - это ячейка общества. Какие ячейки - такое и общество. Так из запрещенной семейственности и родилась узаконенная».

3. Оправдание работы родственников на одном предприятии, в организации, учреждении: «у меня мама - мой непосредственный начальник, так почему-то пенделей мне достается 
иной раз больше, чем другим таким же подчиненным, хотя работаю не хуже... Так чтобы, как говорится, не стыдно было "за ребенка"... Так что это еще вопрос - плохо или хорошо, когда работают вместе родственники?»; «устраивает всех, кроме тех, кто завидует»; «не хочется брать человека с улицы, если дело очень серьезное, доверить его можешь только брату, дяде, сыну или еще кому-то из родственников, не понимаю, почему родственники не могут быть хорошими сотрудниками? А если на должность назначили, а родня уже работала, что - увольнять только за кровь? Как-то глупо получается»; «необходимо реформировать сам институт найма на работу на государственную (муниципальную) должность: сделать наем на работу публичным и по конкурсу. А глав и работников администраций полностью от этой работы отстранить по причине их зависимости от первого лица».

4. Недоверие к возможности изменить ситуацию с коррупционной составляющей семейственности: «так что, теперь 99 \% мест освободится в мэрии? А нет, 99 \% это с любовницами вместе, а если уберут только родственников, то тогда 30 \% останется!»; «интересно, как отнесутся к этому закону на Кавказе? Даже смешно подумать».

Эффрективность мер должна оцениваться, как предполагается, отсутствием или сведением к минимуму признаков непотизма, клановости, семейственности на всех уровнях государственной власти и, вследствие этого, снижением уровня коррупционности принимаемых решений и распределяемых благ. Реальным доказательствам преимущественной роли родственных связей в структуре коррупционных схем и различных форм иных связей (друзья, любовницы, одноклассники, однокурсники и пр.) должного внимания не уделяется.

Сомнительная эффективность антикоррупционного законодательства в части ограничения семейных связей на уровне государственной службы приводит к нарастанию априори негативных оценок семейных и свойственных отношений в эшелонах исполнительной и законодательной власти, сфрере бизнеса, науке и пр. Общественное мнение формируется на базе изначально отрицательного отношения к обнаруживаемым однофамильцам, занимающим высокие должности. Поиск родственных связей в качестве механизма обвинения в заведомой коррупции широко используется для давления на политических оппонентов, в предвыборных кампаниях.

Семья, являясь естественным источником династического вектора выбора образовательной траектории, преемственности этических и моральных профессиональных норм, наследования «дела», «бизнеса», научных и дипломатических траекторий, под предлогом и давлением нежелательного широкого общественного обсуждения и осуждения, возможного нарушения действующего законодательства осознанно прерывает профессиональные традиции. Мы не можем отрицать факты «сомнительных» назначений или ярких и стремительных карьерных взлетов родственников или близких власти предержащих. Фонд «Петербургская политика» провел исследование о фоорировании новой российской аристократии [25]. Акцент в нем был сделан на анализе путей, методов и тенденций современного процесса смены поколений во властных структурах, проблем наследования профессии и видов деятельности, препятствий или стимулов реализации социальных лифтов, форм восходящей социальной мобильности для молодых поколений. Так называемый аристократический, или династический, вариант наследования статусных позиций рассматривается в настоящее время как один из очевидных путей возникновения социально-политических, управленческих элит. Причинами продвижения на статусные позиции родственников эксперты называют «“Радение родному человечку” (“При мне служащие чужие очень ре́дки. Все больше сестрины, свояченицы детки..."), вспоминается комедия А.С. Грибоедова “Горе от ума"»; организация "собственных команд", диверсифицирующихся в широкие сферы деятельности и влияния; поиск законных путей легализации доходов и преференций; высокая степень доверия к лояльности членов семьи.

Цели наследования семейных достижений формируются из-за желания не только «завещать» благородные ценности и методы, мотивы и ответственность в определенной профессиональной сфере, но и передать «завоеванный» социальный статус, который не должен быть снижен у детей и внуков. «Когда-то крупный партработник обеспечивал своему сыну “должность за границей”, сегодня - высокое место в банке, в фирме, в политической партии. Поэтому все "сладкие места" во власти заняты либо по протекции, либо благодаря собственным капиталам» [26]. Подобная картина характерна для подавляющего большинства стран, независимо от уровня развития и социально-экономической формы хозяйствования. Конкуренция, отбор, экзамен, конкурс, обоснованные критерии отбора, испытательные сроки и прочие фрормы выявления талантливых и перспективных специалистов в идеале должны конкурировать со сложившимися примерами кадровых предпочтений на фоне неэффективной семейственности. Однако социально-культурный, политико-экономический, образовательный капитал детей из высокопоставленных семей, как правило, выше среднестатистического уровня, что в значительной степени может составить им высококонкурентные возможности в любом виде конкурсов и кадровых отборах. Необходимо 
отметить также, что на фоне негативных проявлений непотизма обостряются проблемы для молодого поколения, связанные с реализацией карьерных намерений, закрываются или ограничиваются возможные пути восходящей социальной мобильности, не действуют социальные лифты, что провоцирует нарастание социальной напряженности в молодежной среде.

Анализ принципов формирования династий и их угасания в различных профрессиональных средах показал [27], что в настоящее время трехпоколенные династии чрезвычайно редки в России в связи как с особенностями исторического развития страны, так и с изменениями в мотивационной сфере молодого поколения, отрицающего необходимость и желаемость наследования профессии родителей ввиду конфликта интересов, характеристик современного социума и путей социализации молодежи. Система законодательного противодействия созданию семейных династий в сфере государственной службы и чиновничества, остро негативное психологическое отношение общества к процессам аристократизации в современных условиях не препятствуют усилению коррупции.

Негативные и позитивные черты, проявляющиеся в конфликте феноменов династийности и семейственности, требуют детальных многофункциональных исследований и осмысления в контексте глобальных интересов общества и локальных интересов семьи.

\section{Ссылки:}

1. Профессиональные группы в модернизирующемся российском обществе [Электронный ресурс] : монография / А.С. Голубева и [др.] ; отв. ред. В.А. Мансуров. М., 2018. 220 с. // Институт социологии ФНИСЦ РАН : официальный портал. 2018. 27 дек. URL: https://www.isras.ru/files/File/publ/Professionalnye gruppy 2018.pdf (дата обращения: 23.04.2020).

2. Шаманин Н.В. Психологические особенности трансформаций специфических феноменов профессионального самоопределения в различных типах семей (на материале династий) // Экономика образования. 2012. № 4. С. 181-184.

3. Инженерные династии России : монография / науч. ред. В.А. Мансуров. М., 2017. 331 с.

4. Муштук О.3. Непотизм и кумовство как разновидность коррупции на российском фоне // Концептуал : сборник научных трудов кафедры философрии и истории. Московский фринансово-промышленный университет «Синергия» / сост. А.В. Матюхин. М., 2016. С. 451-463.

5. Филиппов В.В. Непотизм на государственной службе в США: противодействие коррупции // Власть и управление на Востоке России. 2015. № 1 (70). С. 142-148.

6. Декрет о недопустимости совместной службы родственников в советских учреждениях [Электронный ресурс]. 1918. 27 июля // Электронная библиотека исторических документов. 2017. 27 нояб. URL: http://docs.historyrussia.org/ru/nodes/12367-27-iyulya-dekret-o-nedopustimosti-sovmestnoy-sluzhby-rodstvennikov-v-sovetskih uchrezhdeniyah\#mode/inspect/page/2/zoom/4 (дата обращения: 24.04.2020).

7. О совместной службе родственников в Советских Учреждениях [Электронный ресурс] : декрет СНК РСФСР от 16 июня 1920 г. Доступ из справ.-правовой системы «КонсультантПлюс».

8. Временные правила о службе в государственных учреждениях и предприятиях [Электронный ресурс] : декрет СНК РСФСР от 21 дек. 1922 г. Доступ из справ.-правовой системы «КонсультантПлюс».

9. Кодекс законов о труде РСФСР [Электронный ресурс] : от 1 апр. 1972 г. // Библиотека нормативно-правовых актов CCCP. URL: http://www.libussr.ru/doc_ussr/usr_7723.htm (дата обращения: 24.04.2020).

10. Об уничтожении сословий и гражданских чинов [Электронный ресурс] : декрет ВЦИК, СНК РСФСР от 10 нояб. 1917 г. Доступ из справ.-правовой системы «КонсультантПлюс».

11. Об изъятиях из правила об ограничении совместной службы родственников [Электронный ресурс] : постановление Совета министров РСФСР от 21 авг. 1972 г. № 510 : в ред. постановлений Совета министров РФ от 23 окт. 1972 г. № 661 : 23 марта 1973 г. № 155 : 10 мая 1973 г. № 243 : 12 окт. 1981 г. № 558 : 31 мая 1991 г. № 301 : 11 окт. 1993 г. № 1027 // Ассоциация лесопользователей Приладожья, Поморья, Прионежья. URL: http://www.alppp.ru/law/trud-izanjatost-naselenija/trud/33/postanovlenie-sovmina-rsfsr-ot-21-08-1972--510.html (дата обращения: 24.04.2020).

12. Зайков Д.Е. Противодействие непотизму в трудовых отношениях: правовое регулирование и проблемы правоприменения // Право. Журнал Высшей школы экономики. 2017. № 2. С. 102-115.

13. Трудовой кодекс РФ [Электронный ресурс] : федер. закон от 30 дек. 2001 г. № 197-ФЗ. Ст. З. Запрещение дискриминации в cфрере труда // Библиотекарь.py. URL: http://www.bibliotekar.ru/trudovoy-codex (дата обращения: 24.04.2020).

14. Там же.

15. О внесении изменений в отдельные законодательные акты РФ в части установления обязанности лиц, замещающих государственные должности, и иных лиц сообщать о возникновении личной заинтересованности, которая приводит или может привести к конфликту интересов, и принимать меры по предотвращению или урегулированию конфликта интересов [Электронный ресурс] : федер. закон от 5 окт. 2015 г. № 285-Ф3. Доступ из справ.-правовой системы «Гарант»; О государственной гражданской службе РФ [Электронный ресурс] : федер. закон от 27 июля 2004 г. № 79-Ф3 : в ред. от 16 дек. 2019 г. Ст. 16. Ограничения, связанные с гражданской службой. Доступ из справ.-правовой системы «КонсультантПлюс».

16. О противодействии коррупции [Электронный ресурс] : феедер. закон от 25 дек. 2008 г. № 273-Ф3 : в ред. от 16 дек. 2019 г. Доступ из справ.-правовой системы «КонсультантПлюс».

17. О распространении на отдельные категории граждан ограничений, запретов и обязанностей, установленных федеральным законом «О противодействии коррупции» и другими федеральными законами в целях противодействия коррупции [Электронный ресурс] : постановление Правительства РФ от 5 июля 2013 г. № 568 : с изм. и доп. Доступ из справ.правовой системы «КонсультантПлюс».

18. ЦИи. по: Зайков Д.Е. Указ. соч. С. 111

19. В РФ безгранично расширили советский запрет на «совместную службу родственников в одном учреждении» [Электронный ресурс] // Право.ру. 2015. 16 июня. URL: https://pravo.ru/news/view/119343 (дата обращения: 24.04.2020).

20. Дюрягина К. Идеальный прокурор - круглый сирота. Сенаторы предлагают скорректировать нормы о конфликте интересов [Электронный ресурс] // Коммерсантъ. 2019. 27 нояб. URL: https://www.kommersant.ru/doc/41721269 (дата обращения: 24.04.2020). 
21. Более трети россиян назвали проблему коррупции в России неискоренимой [Электронный ресурс] // Интерфакс. 2014. 18 нояб. URL: https://www.interfax.ru/russia/407750 (дата обращения: 24.04.2020) ; Коррупция в системе государственной власти [Электронный ресурс] // Левада-центр. 2014. 18 нояб. URL: https://www.levada.ru/2014/11/18/korruptsiya-v-sistemegosudarstvennoj-vlasti (дата обращения: 24.04.2020).

22. Семейственность на работе и в Госдуме. Нужно ли запретить членам одной семьи быть депутатами в Госдуме? [Электронный ресурс] // Фонд «Общественное мнение». 2012. 20 окт. URL: https://fom.ru/Rabota-i-dom/10667 (дата обращения: 24.04.2020).

23. Профессиональная этика и родственные связи: единство или борьба противоположностей? [Электронный ресурс] // ВЦИОМ. 2012. 18 сент. URL: https://wciom.ru/index.php?id=236\&uid=1292 (дата обращения: 24.04.2020).

24. Муниципальным чиновникам запретили брать на работу близких родственников (Форум) [Электронный ресурс] // Rugrad.eu. 2011. 24 окт. URL: https://rugrad.eu/news/450578 (дата обращения: 24.04.2020) ; По закону советского времени близкие родственники не могли работать на одном предприятии [Электронный ресурc] // Mail.ru : фpopym. URL: https://touch.otvet.mail.ru/question/37327185 (дата обращения: 24.04.2020) ; Про клановое правосудие и семейственность [Электронный ресурс] // Maxpark.com. 2012. 15 авг. URL: https://maxpark.com/community/8/content/1455301 (дата обращения: 24.04.2020).

25. Преемники 2.0 (аристократы) [Электронный ресурс] : доклад // Фонд «Петербургская политика». 2018. 30 мая. URL: https://fpp.spb.ru/sites/fpp.spb.ru/files/fpp-aristocrats.pdf (дата обращения: 24.04.2020).

26. Кончаловский А. «Непотизм» как кадровая политика [Электронный ресурс] // Продюсерский центра А. Кончаловского. 2008. 20 марта. URL: http://www.konchalovsky.ru/works/articles/nepotizm (дата обращения: 24.04.2020).

27. Профессиональные группы ...

Редактор: Тюлюкова Мария Олеговна Переводчик: Мельников Евгений Вячеславович 